\title{
Cost variation analysis of oral anti-dyslipidaemic drugs available in Indian pharmaceutical market
}

\author{
Shilpa Jain*, J. L. Marko \\ Department of Pharmacology, Gandhi Medical College, Bhopal, Madhya Pradesh, India
}

Received: 06 February 2020

Accepted: 12 March 2020

*Correspondence:

Dr. Shilpa Jain,

Email: drshilpajain768@gmail.com

Copyright: $(\odot$ the author(s), publisher and licensee Medip Academy. This is an open-access article distributed under the terms of the Creative Commons Attribution Non-Commercial License, which permits unrestricted non-commercial use, distribution, and reproduction in any medium, provided the original work is properly cited.

\begin{abstract}
Background: Dyslipidaemia is one of major risk factor contributing to cardiovascular disease, which further causes mortality and morbidity, so requires a long course of treatment. Physicians should be aware of the cost of drugs.

Methods: Cost of the oral anti-dyslipidaemic drug, either as single drug or in combination manufactured by different pharmaceutical companies in the same strength and dosage form was obtained from current index of medical specialities (CIMS) April-July 2019. The difference in the maximum and minimum price of the same drug manufactured by different pharmaceutical companies and percentage cost variation per 10 tablets was calculated.

Results: In this study, existing findings showed a wide cost variation among different brands of the same oral antidyslipidaemic drug. Percentage cost variation for individual oral anti-dyslipidaemic drug was found to be highest with atorvastatin ( $80 \mathrm{mg}$ film coated (FC) tablet): $358.84 \%$ followed by atorvastatin ( $5 \mathrm{mg}$ FC tablet): $247 \%$, fenofibrate (200 mg FC tablet): $134.22 \%$, lovastatin (10 mg FC tablet): $108.56 \%$, rosuvastatin (10 mg FC tablet): $78.60 \%$, while lowest cost variation is seen with rosuvastatin $40 \mathrm{mg}$ FC Tb: $1.598 \%$. Among fixed dose combination therapy percentage cost variation was found to be highest with atorvastatin and fenofibrate (10 mg and $160 \mathrm{mg}$, FC tablet): $256 \%$, followed by atorvastatin and ezetimibe $(10 \mathrm{mg}$ and $10 \mathrm{mg}$, tablet): $132.39 \%$, while minimum cost variation was for rosuvastatin and fenofibrate (10 $\mathrm{mg}$ and $67 \mathrm{mg}$, tablet): $22.6 \%$.

Conclusions: These study findings showed that there is a wide variation in the cost of the same oral antidyslipidaemic drug. So, it is very necessary for regulatory authorities to regulate the wide variation in the cost, as well as physicians, should be sensitized to be aware of their cost variations to reduce the economic burden of drug-therapy to the patients.
\end{abstract}

Keywords: Cost analysis, Cost variation, Anti-dyslipidaemic drugs, Percentage cost variation

\section{INTRODUCTION}

Dyslipidaemia is one of major risk factors, contributing atherosclerosis and atherosclerosis induced conditions as cardiovascular and cerebrovascular diseases. Ischemic cardiovascular and cerebrovascular diseases are leading causes of morbidity and mortality in the world. Raised plasma triglyceride (TG) levels, raised plasma cholesterol $(\mathrm{CH})$ levels or low plasma high density lipoproteins cholesterol (HDL-CH) levels are independent high-risk factors for coronary artery disease (CAD) and stroke. ${ }^{1}$
Among various anti-dyslipidaemic drugs, statins have been found to reduce the risk of subsequent ischemic cardiovascular and cerebrovascular events and nonhaemorrhagic stroke in virtually every type of dyslipidaemia. Therefore, statins are the first line drugs among different classes of lipid lowering agents. ${ }^{2}$

Pharmacoeconomics is an important and essential tool in therapeutic decision making especially in developing countries. Drug's cost is influencing factor for adherence to treatment and also contributes as essential part of rational drug prescription. Indian pharmaceutical industry 
has a large number of branded formulations for oral antidyslipidaemic drug with wide cost variations between the different brands of same formulations. This difference in cost has resulted in unnecessary economic burden on patients. ${ }^{3}$

High cost of health care is an important issue in policy making for service providers. ${ }^{4}$ Drug price control order (DPCO) regulates the drug prices to make sure to affordability to improve health care facilities. Dyslipidaemia requires a long course of treatment, so adherence to treatment is must for succeed of treatment of dyslipidaemia. ${ }^{5}$ Higher cost of drugs leads to nonadherence to treatment and as a consequence, treatment failure leads to further complications of disease. Therefore, it is essential to create awareness about pharmaco-economics of drug therapy of any disease among physicians to decrease economic burden on patients to ensure patient adherence for treatment and to decrease rate of treatment failure. Hence, this study was taken up to find out variations in cost of drugs for dyslipidaemia available in Indian market either as single drug or in combination to evaluate the difference in cost of various brands of drugs for dyslipidaemia of same formulation by calculating cost ratio and percentage variation in cost in Indian rupees.

\section{METHODS}

This study was analytical study. Cost of drugs for dyslipidaemia, available in Indian market either as a single drug or in combination, manufactured by different pharmaceutical companies in the same strength and dosage forms was obtained from CIMS April-July 2019 edition to analyse the maximum and minimum price in INR per 10 tablets. $^{6}$

Oral anti-dyslipidaemic drugs formulation of same strength and dosage forms as a single drug or in combination manufactured by different pharmaceutical companies were included and drugs formulation being manufactured by only one company were excluded. The difference in the maximum and minimum price of the same drug manufactured by different pharmaceutical companies and cost ratio, percentage variation in cost per 10 tablets was calculated. The cost ratio of same oral anti-dyslipidaemic drug was calculated as follows:

$$
\text { Cost ratio }=\frac{\text { maximum cost }}{\text { minimum cost }}
$$

Percentage cost variation was calculated as follows:

$$
\text { (\%) Cost variation }=\frac{\text { maximum cost }- \text { minimum cost }}{\text { minimum cost }} \times 100
$$

\section{RESULTS}

The prices of drugs for dyslipidaemia manufactured by different pharmaceutical companies were analysed.

Table 1 shows cost ratio and percentage cost variation of drugs for dyslipidaemia used as monotherapy. This study showed a wide variation in cost of same drug for dyslipidaemia manufactured by different pharmaceutical companies, available in the Indian market.

\begin{tabular}{|c|c|c|c|c|c|c|c|}
\hline Drugs & $\begin{array}{l}\text { Dose } \\
(\mathrm{mg})\end{array}$ & $\begin{array}{l}\text { Minimum cost } \\
\text { (INR) }\end{array}$ & $\begin{array}{l}\text { Maximum cost } \\
\text { (INR) }\end{array}$ & Cost ratio & $\begin{array}{l}(\%) \text { cost } \\
\text { variation }\end{array}$ & Brands & Dosage form \\
\hline \multirow{5}{*}{ Atorvastatin } & 5 & 17 & 58.99 & 3.47 & 247 & 9 & \multirow{5}{*}{ *FC-Tab } \\
\hline & 10 & 25.50 & 69.64 & 2.73 & 173 & 12 & \\
\hline & 20 & 49.80 & 139.72 & 2.80 & 180 & 10 & \\
\hline & 40 & 79.00 & 202.85 & 2.56 & 156 & 10 & \\
\hline & 80 & 117.33 & 532.50 & 4.52 & 353.84 & 6 & \\
\hline \multirow{4}{*}{ Rosuvastatin } & 5 & 52.80 & 87.26 & 1.65 & 65.26 & 4 & \multirow{4}{*}{ *FC-Tab } \\
\hline & 10 & 85.80 & 153.33 & 1.78 & 78.60 & 4 & \\
\hline & 20 & 166 & 240 & 1.44 & 44.57 & 4 & \\
\hline & 40 & 438 & 445 & 1.01 & 1.598 & 2 & \\
\hline \multirow{3}{*}{ Simvastatin } & 5 & 62 & 62.10 & & & 2 & \multirow{3}{*}{$* * \mathrm{Tab}$} \\
\hline & 10 & 97 & 107.16 & 1.104 & 10.47 & 2 & \\
\hline & 20 & 154.6 & 163.9 & 1.06 & 6.01 & 2 & \\
\hline \multirow{2}{*}{ Lovastatin } & 10 & 35.96 & 75 & 2.08 & 108.56 & 3 & \multirow{2}{*}{ **Tab } \\
\hline & 20 & 79 & 125 & 1.58 & 58.22 & 3 & \\
\hline Fenofibrate & 200 & 71.4 & 167.24 & 2.34 & 134.22 & 3 & $* * *$ Cap \\
\hline
\end{tabular}

Table 1: Variation in cost of drugs for dyslipidaemia.

*FC-Tab: Film coated tablet, **Tab: Tablet, ***Cap: Capsule.

For oral anti-dyslipidaemic drugs used as monotherapy, percentage cost variation was found as follows: atorvastatin: (5 mg FC tablet: $247 \%)$, (10 mg tablet: $173 \%)$, (20 mg tablet: $180 \%)$, (40 mg tablet: 156\%), (80 mg tablet: $353.84 \%$ ), rosuvastatin: (5 mg fc tablet: 65.26\%), (10 mg tablet: $78.6 \%)$, (20 mg tablet: $44.57 \%)$, (40 mg tablet: 1.58\%), lovastatin: (10 mg tablet: 108.56\%), (20 mg: 58.22\%), simvastatin: (10 mg tablet: 
10.47\%), (20 mg tablet: $6.01 \%$ ), fenofibrate: (200 mg capsule: $134.22 \%)$. The highest percentage cost variation was found for atorvastatin $80 \mathrm{mg}$ FC tablet: $353.84 \%$, where lowest percentage cost variation was found for rosuvastatin $40 \mathrm{mg} \mathrm{FC} \mathrm{Tb:} 1.598 \%$.

Table 2: Cost variation of fixed dose combination of oral anti-dyslipidaemic drugs.

\begin{tabular}{|llllllll|}
\hline Drugs & $\begin{array}{l}\text { Dose } \\
(\mathbf{m g})\end{array}$ & $\begin{array}{l}\text { Minimum } \\
\text { cost (INR) }\end{array}$ & $\begin{array}{l}\text { Maximum } \\
\text { cost (INR) }\end{array}$ & $\begin{array}{l}\text { Cost } \\
\text { ratio }\end{array}$ & $\begin{array}{l}\text { (\%) cost } \\
\text { variation }\end{array}$ & $\begin{array}{l}\text { Brands } \\
\text { Dosage } \\
\text { form }\end{array}$ \\
\hline Atorvastatin & $10+10$ & 71 & 1.65 & 2.32 & 132.39 & 14 & *FC-Tab \\
\hline Ezetimibe & $20+10$ & 141.53 & 237.5 & 1.67 & 67.80 & 2 & \\
\hline Atorvastatin & $10+160$ & 58 & 207 & 3.56 & 256.89 & 14 & $*$ Tab \\
\hline Micronized & $10+200$ & 82 & 145.28 & 1.73 & 77.17 & 2 & $*$ FC- Tab \\
\hline Fenofibrate & $10+160$ & 208.4 & 330 & 1.50 & 58.34 & 2 & $*$ Tab \\
\hline $\begin{array}{l}\text { Rosuvastatin } \\
\text { and }\end{array}$ & $10+67$ & 157.3 & 193 & 1.22 & 22.69 & 2 & $*$ Tab \\
\hline Fenofibrate & $10+145$ & 105.71 & 142.68 & 1.34 & 34.97 & 3 & $*$ Tab \\
\hline
\end{tabular}

*FC-Tab: Film coated tablet, **Tab: Tablet.

Table 2, is showing percentage cost variation of oral antidyslipidaemic drugs, used as fixed dose combinations. Percentage cost variation of oral anti-dyslipidaemic drugs used as fixed-dose-combinations was found to be atorvastatin and fenofibrate: $(10 \mathrm{mg}$ and $160 \mathrm{mg}$ tablet: 256.89\%), (10 mg and $200 \mathrm{mg}$ FC tablet: $77.17 \%)$, atorvastatin and micronized fenofibrate: $(10 \mathrm{mg}$ and 160 mg micronized tablets: 58.34\%), atorvastatin and ezetimibe: (10 mg and $10 \mathrm{mg}$ FC tablet: 132.39\%), (20 $\mathrm{mg}$ and $10 \mathrm{mg}$ FC tablet: $40.66 \%$ ), rosuvastatin and fenofibrate: (10 mg and $67 \mathrm{mg}$ tablet: $22.69 \%),(10 \mathrm{mg}$ and 145 FC tablet: $34.97 \%)$, (10 mg and 160 FC tablet: $87.3 \%$ ). The highest percentage cost variation was found for atorvastatin and fenofibrate $(10 \mathrm{mg}$ and $160 \mathrm{mg}$ tablet: $256.89 \%$ ) and lowest percentage cost variation was found for rosuvastatin and fenofibrate $(10 \mathrm{mg}$ and 67 FC tablet: $22.69 \%$.

\section{DISCUSSION}

In India, a particular drug is manufactured and sold by a number of pharmaceutical companies. So, there is a wide variation in prices of same drug for dyslipidaemia manufactured by different pharmaceutical companies, available in Indian market. Variations in prices of a particular drug have economic impacts on Indian population.

This study found a large variation in maximum and minimum prices of oral drugs for dyslipidaemia used as both monotherapy and fixed dose combination. For most of oral anti-dyslipidaemic drug percentage cost variation was above $100 \%$ and there is wide variation in cost of different brands of same drug for dyslipidaemia in India which is in accordance with the results obtained from previous studies. ${ }^{7,8}$ Findings similar to this study were seen with cost variation analysis studies on antibiotics, antihypertensives and antidiabetic drugs etc. ${ }^{9-11}$

Higher costs of medication have been found to be a reason for medication non-adherence. ${ }^{12}$ Non adherence to treatment regimen lead to progression of diseases and its complications and then it not only remains as health issues, it leads to many social, mental, emotional impacts on not only patients, rather on its family, society too. In Indian scenario, non-adherence to treatment due to higher cost is much more then developed countries because here in India most of patients are not covered by insurance schemes, they have to pay at their own. In such scenario prescribing costly brands leads to unnecessary economic burden to the patient and lead to make things complicated. There should be provision of drug manual with comparative prices and there should be sensitization among physicians about pharmaco-economics aspects of drugs by improving these situations.

In India there is drug price control order (DPCO) is an order issued by Indian government to fix prices of drugs. If a drug is brought under DPCO, it cannot be dispensed at price higher that is fixed by the government of India. ${ }^{13}$ But at present there are very few oral anti-dyslipidaemic drugs which are covered under DPCO, this factor is responsible for huge cost variations among different brands. Hence, it becomes essential to drag government's attention to bring uniformity in drug pricing.

\section{CONCLUSION}

This study finding showed a wide variation in the cost of same oral drugs for dyslipidaemia manufactured by different pharmaceutical companies available in Indian market. Thus, it is essential to create awareness and sensitization not only among physicians, rather among policy makers, agencies, government agencies, general public. So that appropriate interventions can be taken to reduce economic burden to patients and health care system of country. In India it is must to develop a platform for understanding every aspect of pharmacoeconomics with appropriate methodology and training.

\section{Limitations}

Limitations of this study is that sources of information in the study were limited to CIMS, but there are some other brands which are available in Indian market but not published in CIMS. 


\section{ACKNOWLEDGEMENTS}

The authors would like to thank faculties of the department of pharmacology, Gandhi medical college and associated Hamidia hospital, Bhopal, for their immense support in conducting the study.

Funding: No funding sources

Conflict of interest: None declared

Ethical approval: The study was approved by the Institutional Ethics Committee

\section{REFERENCES}

1. Tripathi KD. Essentials of Medical Pharmacology (8th Edition). 2019.

2. Dandan HR, Brunton L. Goodman and Gilman Manual of Pharmacology and Therapeutics. Philadelphia: McGraw Hill Professional; 2013: 852854.

3. Mandal DSC. A critical study on availability and price variation between different brands: Impact on access to medicines. Indian $\mathrm{J}$ Pharmaceutical Sci. 2007;69(1):160.

4. Gupta SK. Proposel Pharmaco-economics Guidelines for India (PEG-I). IpSOR India. 2013;79:100.

5. Shrank WH, Hoang T, Ettner SL, Glassman PA, Nair $\mathrm{K}$, Lapp DD, et al. The implications of choice: Prescribing generic or preferred pharmaceuticals improves medication adherence for chronic conditions. Arch Intern Med. 2006;1663(3):332-7.

6. Current Index of Medical Specialities; 2019: 142146.
7. Chawan VS, Sharma P. Cost variation analysis of oral hypolipidemic agents available in India. Int $\mathbf{J}$ Basic Clinical Pharmacol. 2014;3.

8. Shukla, Ajay, Sharma, Parag. Cost variation analysis of antidyslipidemic drugs. Int $\mathrm{J}$ Basic Clin Pharmacol. 2016.

9. Shah, Zubin, Apurva D, Londhe VY. Pharmacoeconomic study of various brands of antibiotic medications in India. 2015.

10. Kamath L, Satish GR. Cost Variation Analysis of Antihypertensive Drugs Available in Indian Market: An Economic Perspective. Int J Pharm Sci Res. 2016;7(5):2050-56.

11. Lalan H, Borde, Manjusha, Mohanty R, Ipseeta, Deshmukh Y. Cost Variation Study of Antidiabetics: Indian Scenario. Indian J Applied Res. 2014;4(5):420-1.

12. Ho P, Michael, Chris L, Bryson, Rumsfeld JS. Medication adherence: its importance in cardiovascular outcomes. Circulation. 2009;119(23):3028-35.

13. National Pharmaceutical Pricing Authority, Government of India. Available at: http://nppaindia.nic.in/DPCO-2013. Accessed on 15 April 2019.

Cite this article as: Jain S, Marko JL. Cost variation analysis of oral anti-dyslipidaemic drugs available in Indian pharmaceutical market. Int J Basic Clin Pharmacol 2020;9:753-6. 